\title{
HOTEL'S WEB SITE HEALTH AUDIT AND PAGES DISTRIBUTION BY THEIR STATUS: AN EMPIRICAL RESEARCH OF FIVE STAR HOTELS IN THE REPUBLIC OF CROATIA
}

\author{
Mislav Šimunić
}

https://doi.org//10.20867/tosee.06.49

\begin{abstract}
Purpose - The purpose of this paper is to indicate the importance of direct online booking in the structure of hotel online booking channels. In this context, this paper explores the relationship between quality of websites and the amount of online direct bookings through hotel websites. Methodology - Empirical Research was conducted by qualitative multidimensional analysis of 5* hotel websites in the Republic of Croatia. This process is made up of numerous analytical subprocesses such as web site health, user engagement, user experience, traffic, functionality, website performance and other. In this paper the focus is on the Hotel's web site healt audit. Hotel's web site health audits aims to analyze the overall health of web pages within web site while discovering all issues that hotel should be aware of. The authors' research was conducted using Semrush analytical platform for improving search engine visibility.

Findings - The results of the empirical research show the distribution of web pages within the analyzed web sites according to their qualitative status. Interpretation of the research results explains the impact on the structure of online booking channels in hotel business and applicability in theory and practice.

Contribution - The scientific contribution stems from empirical research that defines the way and space to improve direct online hotel bookings through own web site in terms of improving web site performances.
\end{abstract}

Keywords: hotel, online direct booking, website audit, visibility (Search Engine Result Page), KPI.

\section{INTRODUCTION}

The hotel as a business system can sell/offer its capacity through direct and indirect booking channels. Each of these channels has specifics manifested by advantages and disadvantages. In this paper, the focus is on examining the importance of the hotel website as a direct sales channel and the elements that determine it. Considering the hotel website as a booking channel is a very complex task. The website as a booking channel should not be considered as a separate entity, but as a part of a complex system consisting of the Internet (as a platform), www (as one of the main services), search engines (Google, Baidu, Yandex, Microsoft Bing, YouTube, Amazon, ...), many specific apps, millions of hotel websites (as multimedia information models) and potential hotel guests as website and information users. In this complexity of mutual relationships, each individual hotel website has a specific purpose (informing and inspiring action) and value 
ToSEE - Tourism in Southern and Eastern Europe, Vol. 6, pp. 739-756, 2021.

M. Šimunić: HOTEL'S WEB SITE HEALTH AUDIT AND PAGES DISTRIBUTION BY THEIR ...

(content and technical). This value / quality of the website (which is a prerequisite for business success and can be observed from many different aspects, such as the visibility of the website in search engines, which depends on OnSite and OffSite SEO - Search Engine Optimization, SEM - Search Engine Marketing, website "health", website UX User Experience, website UI - User Interface, etc.) is crucial for visibility within Google SERP - Search Engine Resault Pages in organic / algorithmic search. Visibility within the search engine determines traffic to the website. The number of conversions depends on the website traffic. The number of conversions directly affects the most important Key Performance Factors (KPIs) in the hotel industry (Avg. Occ. - Average Occupancy Rate, ADR - Average Daily Rate, RevPAR - Revenue per Available Room, TrevPAR Total Revenue per Available Room, Total Revenue per Overnight) as it is a percentage in relation to the number of visitors. In this sense, it should be emphasized that in the Republic of Croatia and this part of Europe, the most dominant search engine is Google with more than 3.5 billion individual searches (search queries) on their platform every day (Mohsin 2020). The research in this work is based on Google rules, procedures and algorithms (where only algorithmic / organic search is analyzed, not the program Google Ads).

Therefore, the Google algorithm is responsible for the position of the web site / web pages within the organic / algorithmic search results. Google uses more than 200 ranking factors in its algorithm. The frequently asked question is what exactly are these factors and "how do they work"? There are many sources that research ranking factors. To understand the whole problem of the functioning of the Google algorithm, it is very important to constantly study the problem, create new metric models and use authentic and credible sources that research Google ranking factors (Robinson 2019). But why is this important for the hotel business? It is in the interest of every hotel to achieve the best possible business result with an optimal combination of sales / booking channels. In this paper, the focus is on researching the importance of the hotel web site quality with the purpose of a positive effect on the hotel business result. In this regard, it is important to answer the research questions: (1) Is there a relationship between the quality of hotel web sites and the distribution structure of hotel online booking/sales channels and (2) is it possible to identify potential and define the direction of improving direct online hotel sales through complex analysis of hotel web sites quality.

\section{THEORETICAL BACKGROUND AND LITERATURE REVIEW}

As written earlier, one of the main purposes of the hotel as a business system is to sell as many rooms as possible at the best possible price (Connally 2021). The introduction of computer reservation systems (CRS) and Global Distribution Systems (GDS), followed by the development of the Internet and online sales channels, have dramatically changed the best operational and strategic practices in the industry (Buhalis and Law 2008). In this sense, Table 1 shows and describes the characteristics of hotel booking channels and marketing triggers. 
ToSEE - Tourism in Southern and Eastern Europe, Vol. 6, pp. 739-756, 2021.

M. Šimunić: HOTEL'S WEB SITE HEALTH AUDIT AND PAGES DISTRIBUTION BY THEIR ...

Table 1: Hotel bookings channels and marketing triggers

\begin{tabular}{|c|c|}
\hline ON line DIRECT & commission $0 \%$ \\
\hline $\begin{array}{l}\text { Hotel Web Site } \\
\text { (Through: Channel Manager, PMS, } \\
\text { Web Site Booking Engine ) } \\
\text { Email, Travel Blogs, Travel Forum, Social } \\
\text { Media, Online Ads, Guest Reviews }\end{array}$ & $\begin{array}{l}\text { SEO techniques take time to show results, but it is the } \\
\text { best long-term paid strategy to improve your ranking } \\
\text { and appear higher in search results. Visitors should be } \\
\text { able to find the information they are looking for } \\
\text { quickly and easily, with as few clicks as possible. }\end{array}$ \\
\hline ON line INDIRECT & avg. commission $15-20 \%$ \\
\hline $\begin{array}{l}\text { OTA's Online Travel Agencies } \\
\text { Booking.com } 15 \% \text { and more, Expedia } 15 \% \text { and } \\
\text { more, Airbnb 3\% host fee, and 6-8\% guest fee, } \\
\text { Agoda } 15 \% \text {, Hostelworld.com } 15 \% \text {, Trip.com } \\
\text { 20\%, Laterooms.com } 15 \% \text {, Edreams.com } 20 \% \text {, } \\
\text { ect. }\end{array}$ & $\begin{array}{l}\text { For the hotel, appearing on the OTA is free, but you } \\
\text { will have to pay a commission of about } 15 \% \text { to } 20 \% \\
\text { for each booking. } \\
\text { The fastest option. }\end{array}$ \\
\hline $\begin{array}{l}\text { MSE- MetaSearch Engines } \\
\text { Trivago, Kayak, Skyscanner, TripAdvisor, } \\
\text { Google (with Google Hotyel Finder) }\end{array}$ & $\begin{array}{l}\text { To metasearch engines, the hotel pays a fixed amount } \\
\text { for each click, determined by a bidding system (or } \\
\text { PPC "Pay-Per-Click" model). But the question is } \\
\text { whether it is worth it! The hotel must calculate and } \\
\text { decide this for itself! }\end{array}$ \\
\hline $\begin{array}{l}\text { GDS - Global Distribution System } \\
\text { Amadeus, Sabre, Galileo, Worldspan (owned by } \\
\text { Travelport) }\end{array}$ & $\begin{array}{l}\text { Hotels typically sell their rooms } \mathbf{3 0 \%} \text { cheaper at } \\
\text { GDS (compared to public rates). Central Reservation } \\
\text { Services (CRS), such as Sabre, allow hotels to sell } \\
\text { their rooms to all GDS at the same time. Therefore, } \\
\text { small independent hotels usually do not need GDS. }\end{array}$ \\
\hline "OFF line DIRECT & commission $0 \%$ \\
\hline $\begin{array}{l}\text { Telefon, Fax, Walk ins, Repeat Customers, } \\
\text { Word of Mouth, Travel books, Press, Flyers } \\
\text { and Posters }\end{array}$ & $\begin{array}{l}\text { The best marketing you'll ever do is to exceed } \\
\text { expectations and make your customers highly } \\
\text { satisfied - they'll come right back again. } \\
\text { Word-of-mouth and repeat business will always be the } \\
\text { most powerful triggers. }\end{array}$ \\
\hline OFF line INDIRECT & commission $0 \%$ \\
\hline $\begin{array}{l}\text { Develop a partnership with: } \\
\text { Tour Operators, Travel Agencies, Local Tourism } \\
\text { Boards, Event Agency, Tourism Fairs, Local } \\
\text { Companies } \\
\text { Why? } \rightarrow\end{array}$ & $\begin{array}{l}\text { Does "Hotel" know who travelers ask for hotel } \\
\text { recommendations at their destination? Where do } \\
\text { travelers who have not booked a hotel in advance } \\
\text { (walk-ins) arrive first at their destination (airport, train } \\
\text { station, bus station,..)? }\end{array}$ \\
\hline
\end{tabular}

Source: Author's processing according to (Thielin 2020), 4 Hotel Bookings Sources and their Marketing Triggers:(https://www.hotelminder.com/online-offline-direct-indirect-everything-about-your-bookingsources\#1.-direct-and-online:-the-smart-long-term-strategy, accessed: 29.04.2021.

Direct sales through hotel website (via Channel Manager, PMS - Property Management System, Site Booking Engine is the most appreciated concept of hotel sales. It relies on SEO - Search Engine Optimization techniques (OnSite and OffSite) that take time to show results, but it is the best long-term paid strategy to improve your ranking and appear higher in search results (Thielin 2020). The ultimate goal is to convert as many hotel website visitors as possible from potential to active customers/consumers (\% of conversions). The commission is $0 \%$, but there is significant investment in improving and optimizing the website (not only money, but also knowledge, time, tracking trends, tracking the evolution of the Google algorithm, tracking the importance of the Google ranking factor). The fact is that Indirect Sales Channels (Online Travel Agencies as the 
ToSEE - Tourism in Southern and Eastern Europe, Vol. 6, pp. 739-756, 2021.

M. Šimunić: HOTEL'S WEB SITE HEALTH AUDIT AND PAGES DISTRIBUTION BY THEIR ...

most dominant) is now the primary concept and source of hotel bookings. Looking at the ratio of direct and indirect distribution channels in Europe according to Phosuswright (Prieto 2021) we see that the distribution ratio of hotel online bookings for 2017. was OTAs - 69\% and hotel direct bookings 31\%. Moreover, d-edge Hospitality Solutions The Rise of Direct Bookins over OTAs: Hotel distribution trends in EMEA and APAC (d-edge hospitality, 2021) data from an empirical study conducted from 2017 to 2020 (published in November 2020.) based on the collected information from 3400 hotels from Europe (where 5\% are 5* hotels) and 450 hotels from Asia - Pacific region (where $19 \%$ of hotels are $5^{*}$ hotels. The purpose of the research was to understand what is happening with the proliferation of online distribution channels in the hotel industry, while also understanding whether the trends are local or global.

The main indicators that emerge from the analysis of this data and that are relevant to the research conducted in this paper are the following (1) The share of direct revenue from websites has been growing steadily since 2017 in both the EMEA and APAC regions, accelerating in 2020. $(+10 \%)$, (2) In terms of total sales, the share of online sales has not changed significantly over the observed period and is approx. $90 \%$ of total revenue, (3) The share of OTAs in total online revenue has decreased from $69 \%$ in 2019 to $63.3 \%$ in 2021 , while the share of direct revenue via hotel websites has increased from $20.7 \%$ in 2019 to $28.4 \%$ in 2020 , (4) Further examination of the distribution of online distribution channels reveals that direct revenue via hotel websites is taking market share away from OTAs. This trend has accelerated in 2020 , which can probably be explained by the decrease in advertising via OTAs (most likely caused by changes in commercial policy in the face of the Covid 19 pandemic). It can be concluded that when OTA reduce advertising budget, organic / algorithmic search results (within search engine visibility) come to the fore and rank higher in search engines, leading to increased direct online sales through the hotel brand's website. For this reason, it is important to know the Google algorithm factors and how they work. For this reason, this topic will be explained later in the context of harnessing the potential to improve the performance of the hotel business. The hotel industry can be positively impacted by (1) optimizing the penetration of hotel online sales / booking channels and (2) increasing the quality of website elements / Google ranking factors. By increasing the volume of direct online booking channels in the distribution structure of hotel online booking channels, a positive effect on KPI should be achieved.

According to D-edge Hospitality Solutions (d-edge hospitality, 2021), the market share of hotel booking channel distribution (percentage of booking revenue) by cancelation by channel in Europe and Asia Pacific [EMEA, APAC] during the observed period shows the growth of direct distribution (+ 10.1 percentage points) and the decline of booking.com group distribution (-3.8 percentage points). At the same time, empirical research in the Republic of Croatia based on data analysis of the internal structure of hotel booking channels in Croatia (Mihač 2019 and PHOBS Central Reservation System 2020) shows that in 2018. distribution of hotel online booking channels the share of bookings through hotel brand website is $19.23 \%$ and the share of bookings through OTAs - Online Travel Agency s is $66.72 \%$. Data for 2018 shows that $82 \%$ of all travel bookings were made online in 2018 (approximately 148 million bookings) (Deane 2020). 
ToSEE - Tourism in Southern and Eastern Europe, Vol. 6, pp. 739-756, 2021.

M. Šimunić: HOTEL'S WEB SITE HEALTH AUDIT AND PAGES DISTRIBUTION BY THEIR ...

With the rapid development of information and communication technology, the hotel industry is experiencing dramatic changes, especially in the distribution of hotel sales channels (Law et al. 2015). Big players (intermediaries, especially OTAs Online Travel Agencies) are fiercely fighting for the attention of each customer, and all this is ultimately reflected on the success of the hotel business. Through a detailed analysis of booking channels, the hotel as a business system should develop a booking channels management strategy (Fei 2017) that ensures maximum optimal and positive impact on KPIs by constantly improving the value ratio between direct and indirect sales channels in favor of direct sales through the web hotel site. In order to increase the share of sales through the hotel brand's website, the first thing to do is to increase the visibility in search engines (Šimunić 2020), in a way that makes the best use of search engine algorithms. Nowadays, there are many professional tools (usually as SaaS - Software as a Service platform) to improve online visibility and to discover many different marketing insights. Many different tools for analysis, collecting data, comparing data, benchmarking, research, reports,... etc. help hotels as business subjects to work with: Search Engine Optimization, Pay Per Click, Keyword Research, Competitive Research, Campaign Management,... Improve. The author is using Semrush online web platform for his research in recent years, which is one of the best SaaS platforms for visibility management and content marketing. Semrush is an all-in-one SaaS software that allows hotels as business subjects to improve and optimise their online visibility. OnSite and OffSite optimization is an important key to improve KPIs in the hotel business. In the optimization process, all factors (PREbooking factors, DURINGbooking factors, POSTbooking factors) that contribute to the improvement of visibility in search engines should be considered (Šimunić 2019).

The most important Google ranking factor in 2021. is dealt with by (Barysevich 2020), where (among other things) he highlights and explains as a novelty the Page Experience Update as the biggest Google update of the year. Core Web Vitals are part of the update, and they are definitely ranking factors to keep in mind, especially when optimizing images - which is extremely important in the hotel industry. The Google algorithm has over 200 factors that are categorized into their respective groups (Domain Factors, PageLevel Factors, Site-Level Factors, Backlink Factors, User Interaction Factors, Special Google Algorithm Rules, Brand Signals, OnSite and Off-Site WebSpam Factors). The value of the factor changes sometimes several times a day. Some of the factors are proven, some are controversial, and some are SEO nerd speculations (Brian 2020, Nada 2021). Also, for application in practice, it is very important to simultaneously explore both the theoretical and practical aspects. In this context (Alba-Munoz et al. 2021) in their work deal with Web usability where the audit manual is presented using a case study methodology, which combines a theoretical contribution with the contributions of the actual audit of the tourist institution. One truth and fact is undeniable: optimizing a greater number of factors provides better search engine visibility. There are various specific software for the quality analysis of each factor, which allows both the quality analysis and optimization of the measured factor. The development of new metric models also poses challenges to the scientific and professional community working on this topic. 
ToSEE - Tourism in Southern and Eastern Europe, Vol. 6, pp. 739-756, 2021.

M. Šimunić: HOTEL'S WEB SITE HEALTH AUDIT AND PAGES DISTRIBUTION BY THEIR ...

\section{RESEARCH METHODOLOGY}

The research methodology used in this study followed a three-step procedure:

Step 1: Research of previous research and processing of available literature related to the topics addressed in the paper. In this stage, methods of analysis, description, compilation and comparison were used.

Based on the theoretical part of the research through studies of available literature, research concepts, attitudes and ideas (see cited authors in the introduction and chapter 1 the author came to the conclusion that there is a significant impact of technology / internet / www / google algorithm / web sites development on the structure in hotel booking channels ratio and that this fact represents the potential for continuing the empirical part of the research. The theoretical contribution in terms of presenting and comparing previous research results and the views of individual authors with the significance for the research conducted in this paper is emphasized in the first three chapters of this paper.

Step 2: Researching / determining a sample, data source and web address for analysis. This phase also includes the process of collecting, selecting and creating the data set for analysis. At the beginning of this phase, the methods of comparison, analysis and synthesis were used. The method of abstraction was used to deepen the analysis to extract, observe and interpret the main data and its characteristics. A complete research design description of $2^{\text {nd }}$ research phase is described in detail in Chapter 3.

Step 3: In this step, the author summarizes the research findings and outlines the main findings. Also, in this phase, the empirical findings of the research were presented (part of the research results are presented and interpreted in Chapter 3 of this paper while the main thoughts and conclusions are presented in the conclusion of the paper.

\section{RESEARCH, RESULTS AND DISCUSSION}

The study began with an analysis of previous research and available literature. In this way, important insights for further research could be gained. The main conclusions and facts have already been presented in the previous chapters. The following part of the article describes the process of empirical research contributions with the research findings. The empirical research started with collecting the necessary new information about $5^{*}$ hotels in the Republic of Croatia (new hotel list / categorization and hotel URLs). The information was obtained from the Ministry of Tourism of the Republic of Croatia. After collecting the hotel list, the data for $5^{*}$ hotels in Croatia were separated, as they are the subject of research and analysis in this paper. A website URL was also identified for each hotel. Then, a web address for each hotel was entered into the Semrush software for analysis. For each hotel, a project profile was defined with variables for analysis and time periods for receiving thematic reports. The sample includes 39 out of $475^{*}$ hotels in the Republic of Croatia (82.98\% of all $5 *$ hotels). Due to the monitoring and analysis of a large number of parameters this part of the research was conducted from November, 2020 to March, 2021. Statistical analysis modules / projects within 
ToSEE - Tourism in Southern and Eastern Europe, Vol. 6, pp. 739-756, 2021.

M. Šimunić: HOTEL'S WEB SITE HEALTH AUDIT AND PAGES DISTRIBUTION BY THEIR ...

the Semrush SaaS software solution were used to analyze the quality of the websites. A full website audit analysis and Backlinks Audit Analysis was performed in each analytical project (for the website of each $5^{*}$ hotel in the Republic of Croatia). As part of the full-site audit analysis, in addition to analysing errors, warnings, and notices, the following analytical sub-processes were performed in detail: (1) Site Health, (2) Crawlability, (3) HTTPS, (4) International SEO, (5) Core Web Vitals (in beta), (6) Site Performance, (7) Internal Linking and Markup. E.g. the Google Core Web Vitals update is in many ways a response to websites that are not really living up to user expectations. It is a clear message to website owners that not putting users first can negatively impact rankings (Tober 2021). These metrics go beyond page load speed and responsiveness and dig deep into user experience, trying to improve how fast a page loads and how quickly users can interact with it. (Dowson 2021.) A large number of partial "sub"analyzes were performed by this analytic. Backlink Audit Analysis (projects) consisted of the following analyzes: (1) domain toxic score-a (toxic, potentialy toxic \& non-toxic), (2) Follow vs Nofolow backlinks, (3) Anchor types (money, compound, brand, organic, other, naked, empty) \& (4) Top Anchor analyze. In this article, we will pick out and present the variables that are among the most important factors of Google algorithm. Figure 1 shows an example of the most important Google ranking factors and their weight value (weight) within the Google algorithm(s).

Figure 1: The 2021 Google Algorithm Ranking Factors and their Algorithm Weight

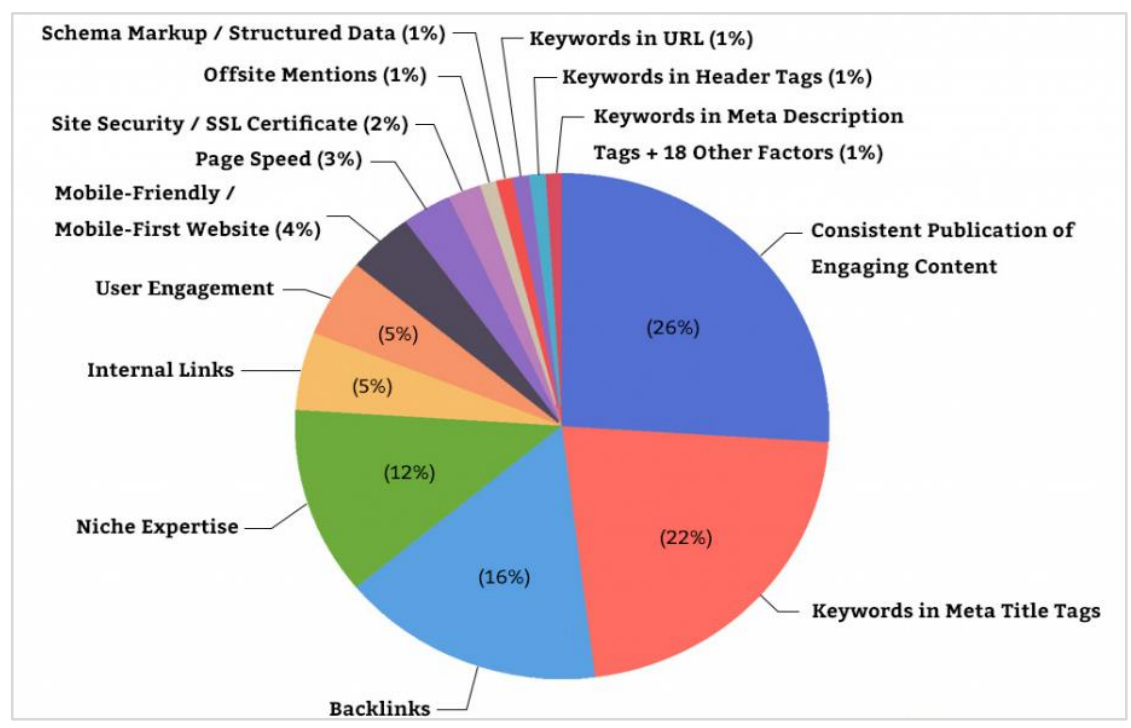

Source: Bailyn E. (2020.),

Numerous authors have considered and researched the issue from different aspects. With regard to the characteristics of this empirical research, in the continuation of this paper, the main presented google ranking factors are explained connecting the specific theoretical aspect and the meaning for the implication in practice. Within the Google algorithm, content is becoming increasingly important. Also, according to (Abiantoro 
ToSEE - Tourism in Southern and Eastern Europe, Vol. 6, pp. 739-756, 2021.

M. Šimunić: HOTEL'S WEB SITE HEALTH AUDIT AND PAGES DISTRIBUTION BY THEIR ...

et. al 2020), content quality is one of the most critical dimensions of website quality and they emphasizes that there are seven indicators to check the quality of the content.

Google tests the content to see if the content matches the search queries. If the queries are answered by the hotel website content, Google rewards this with a better position within the SERP. Generally, Google's Artificial Intelligence (AI) rewards thought leadership content that is produced at least twice a week (Bailyn 2020).

For ranking purposes, it is especially important to include keywords within the title tag. It is best if the title tag contains only the target keyword, but using adjectives around the keyword (understanding the context) is also important for readability. Backlinks have always been a very influential factor within Google's algorithm. But content should be the focus because it creates organic links. In recent years, Google has favored websites that are "authority" / niche in a certain area for certain keywords. When creating content on web pages, it is very important be consistent and use phrases and keywords consistently (content nucleus). Internal links are also a strong boost in Google algorithm. In fact, publishing a large number of articles (web pages within a website) covering a similar / same topic from different points of view, which in turn lead to an authoritative page, gives the website a high value in the Google algorithm and assigns it a higher rank. In order to increase traffic to the hotel website, it used to be very important to create a responsive website (i.e. adaptable to web devices). Today, due to the increase in the use of mobile devices as compared to desktop computers, the visitor using a mobile device is the primary target. The layout of the website should be fairly simple, and the website navigation should be optimized for the mobile user experience. Google's increasingly sophisticated technology and machine learning allow us to treat the quality of the website and based on user activity on the website (for example: bounce rate, time on page, pages per session, are also indicators of the quality of the website content. In this way, Google infers the "level" of satisfaction of the website visitor with a particular website/webpage. SSL certificate (HTTPS) is also becoming one of the most important elements for a position within SERP. The mention of a company/hotel within other pages, but without hyperlinks, is also one of the elements that influence the Google ranking. The best way to influence this element is to create quality content that adds value to other sites (if they mention it). This Google ranking factor is relatively new, but is becoming an increasingly important part of the Google algorithm. Google states that the use of keywords within the title tag, within headings $(\mathrm{H} 1, \mathrm{H} 2, \mathrm{H} 3, \ldots)$ and within Meta Description is still very important, but that it carries little weight within the Google ranking algorithm. However, since nobody knows exactly how the Google ranking algorithm works, these claims should be taken very seriously.

According to (Akhtar 2021), the most important Google ranking factors in 2021 are: (1) High quality content (original, unique, valuable, current / fresh, Content-Length, structure, organization,...), (2) Backlinks, (3) Search Intent (the degree to which the search query matches the content on the website), (4) Website loading speed, (5) Mobile Friendliness, (6) Domain Authority (DA), (7) Keyword Optimization, (8) Website structure (XML sitemap, Robot.txt file for SEO), (9) Website security (HTTPS \& (10) User Experience. 
ToSEE - Tourism in Southern and Eastern Europe, Vol. 6, pp. 739-756, 2021.

M. Šimunić: HOTEL'S WEB SITE HEALTH AUDIT AND PAGES DISTRIBUTION BY THEIR ...

Furthermore, (Dowson 2021) highlights as the 12 most important Google ranking factors: (1) Core Web Vitality, (2) High Quality Content, (3) Keywords in Meta Title Tags, (4) Backlinking, (5) Niche Relevance, (6) Internal Linking, (7) Visitor Time on Page, (8) Mobile Friendliness, (9) Page Load Speed, (10) SSL, (11) Schema Markup \& (12) Keywords in URL, Header Tags and Meta Description.

According to (Hardwick 2021), one of the key specialists on the ahrefs team, the top 10 Google ranking factors include: (1) Backlinks, (2) Freshness, (3) Topical Authority, (4) Search Intent, (5) Content Depth, (6) Page Speed, (7) HTTPS, (8) Mobile Friendliness. (9) User Experience, (10) Content Accuracy. He highlights backlinks as the most important factor and notes that independent research also confirms the relationship between backlinks and organic traffic, including the results of the ahrefs study of over one billion web pages (Figure 2).

Figure 2: Relationship between backlinks (referring domains) and organic traffic

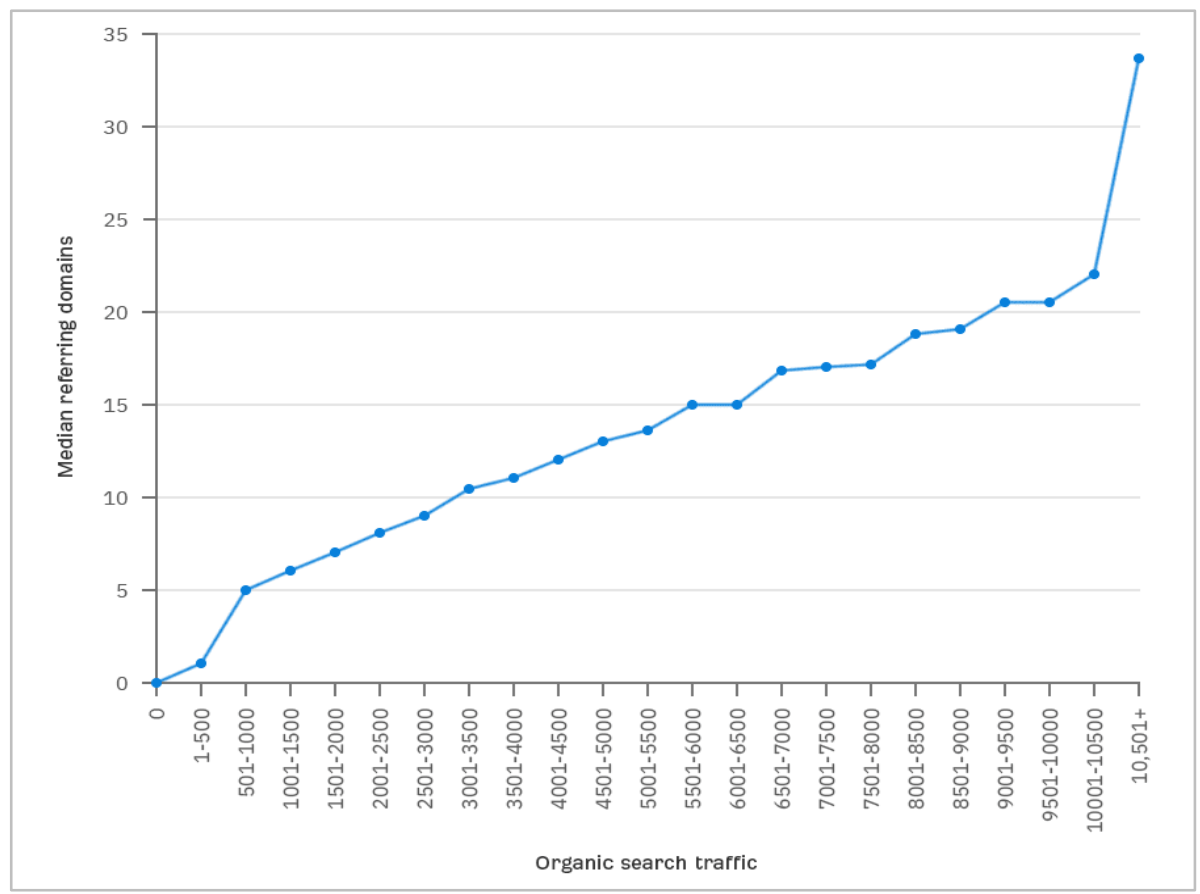

Source: ahrefs, Ahrefs study: https://ahrefs.com/blog/google-ranking-factors/, accessed: 15.04.2021.

However, not all backlinks are created equal. They can also be further analyzed by specifically looking at relevance (link from relevant sites from a particular field) and authority (links from strong sites according to Domain Rating and URL rating). He also cites freshness as a very important factor, as Google knows that people want to see new information. Figure 2 directly shows the impact of backlinks quality (for a particular web site) on visibility within algorithmic / organic search results within SERP - Search Engine Resault Pages. 
ToSEE - Tourism in Southern and Eastern Europe, Vol. 6, pp. 739-756, 2021.

M. Šimunić: HOTEL'S WEB SITE HEALTH AUDIT AND PAGES DISTRIBUTION BY THEIR ...

In their article, Ziakis et al. (2019) investigated the Google ranking factors that have the greatest impact on ranking within the SERP. According to their research, several website variables were cited as factors that influence a website's ranking, with (1) Quality And Quantity of Backlinks, (2) Social Media Support, (3) Keyword In Title Tag, (3) Website Structure, (4) Website Size, (5) Load Time, (6) Domain Age, and (7) Keyword Density being the most frequently cited. Based on the correspondence of the data (1) defined by different authors and (2) the analyzed variables representing metric markers in Semrush analytical processes (which stand out due to the spatial limitation of this article and are considered in this study), the paper provides an investigation of the analytical markers that are simultaneously Google ranking factors and elements of hotel websites.

The basic limitations of this empirical research refer to a relatively small sample of hotels (regardless of the fact that $82.98 \%$ of all $5^{*}$ hotels in Republic of Croatia were analyzed). Future research should take into account groups of other hotel categories and should also expand the geographical area of research.

\subsection{Hotel Web Site Audit - Crawled Pages Analysis}

Crawled pages on websites - includes review as part of the website audit process. This analysis is performed based on parameters used by Googlebot to better understand and more easily index a web page based on a set of metric markers: markup, crawldepth, sitemap, HTTP status codes, AMP links, Internal links, Canonical tag, hreflang tag.

Table 2: Analysis of the crawled pages of a hotel website

\begin{tabular}{|c|c|c|c|c|c|c|}
\hline \multirow[b]{3}{*}{ Hotel } & \multicolumn{6}{|c|}{ SITE AUDIT } \\
\hline & Pages crawled & Healthy & Broken & Have issues & Redirected & Blocked \\
\hline & ws. p.c. num. / g.l. num & $\%$ & $\%$ & $\%$ & $\%$ & $\%$ \\
\hline $\begin{array}{l}\text { H1 } \\
1\end{array}$ & $\begin{array}{ll}100 / 100 \\
\end{array}$ & 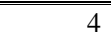 & 15 & 79 & 2 & 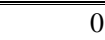 \\
\hline H2 & $25 / 100$ & 0 & 4 & 68 & 28 & 0 \\
\hline H3 & $100 / 100$ & 9 & 0 & 84 & 7 & 0 \\
\hline H4 & $100 / 100$ & 9 & 0 & 84 & 7 & 0 \\
\hline H5 & $100 / 100$ & 9 & 0 & 84 & 7 & 0 \\
\hline H6 & $100 / 100$ & 9 & 0 & 84 & 7 & 0 \\
\hline H7 & $100 / 100$ & 9 & 0 & 84 & 7 & 0 \\
\hline H8 & $65 / 100$ & 2 & 6 & 92 & 0 & 0 \\
\hline H9 & $100 / 100$ & 26 & 1 & 71 & 2 & 0 \\
\hline H10 & $100 / 100$ & 0 & 0 & 90 & 4 & 6 \\
\hline H11 & $100 / 100$ & 1 & 0 & 95 & 3 & 1 \\
\hline H12 & $25 / 100$ & 0 & 4 & 68 & 28 & 0 \\
\hline H13 & $35 / 100$ & 4 & 12 & 88 & 0 & 0 \\
\hline H14 & $100 / 100$ & 1 & 0 & 90 & 1 & 8 \\
\hline H15 & $100 / 100$ & 6 & 0 & 92 & 2 & 0 \\
\hline H16 & $33 / 100$ & 0 & 0 & 100 & 0 & 0 \\
\hline H17 & $26 / 100$ & 4 & 0 & 96 & 0 & 0 \\
\hline H18 & $100 / 100$ & 1 & 0 & 92 & 2 & 5 \\
\hline H19 & $100 / 100$ & 1 & 0 & 92 & 2 & 5 \\
\hline H20 & $100 / 100$ & 0 & 35 & 36 & 19 & 10 \\
\hline H21 & $100 / 100$ & 1 & 0 & 97 & 2 & 0 \\
\hline H22 & $100 / 100$ & 7 & 1 & 88 & 3 & 1 \\
\hline
\end{tabular}


ToSEE - Tourism in Southern and Eastern Europe, Vol. 6, pp. 739-756, 2021.

M. Šimunić: HOTEL'S WEB SITE HEALTH AUDIT AND PAGES DISTRIBUTION BY THEIR ...

Table 2 (continued)

\begin{tabular}{|c|c|c|c|c|c|c|}
\hline \multirow[b]{3}{*}{ Hotel } & \multicolumn{6}{|c|}{ SITE AUDIT } \\
\hline & Pages crawled & Healthy & Broken & Have issues & Redirected & Blocked \\
\hline & ws. p.c. num. / g.l. num & $\%$ & $\%$ & $\%$ & $\%$ & $\%$ \\
\hline $\mathbf{H 2 3}$ & $100 / 100$ & 1 & 6 & 84 & 9 & 0 \\
\hline H24 & $100 / 100$ & 0 & 1 & 76 & 4 & 19 \\
\hline H25 & $100 / 100$ & 7 & 1 & 88 & 3 & 1 \\
\hline H26 & $100 / 100$ & 8 & 6 & 82 & 4 & 0 \\
\hline H27 & $100 / 100$ & 1 & 0 & 96 & 3 & 0 \\
\hline H28 & $100 / 100$ & 8 & 0 & 89 & 3 & 0 \\
\hline H29 & $100 / 100$ & 8 & 0 & 89 & 3 & 0 \\
\hline H30 & $100 / 100$ & 8 & 1 & 91 & 0 & 0 \\
\hline H31 & $100 / 100$ & 1 & 0 & 96 & 3 & 0 \\
\hline H32 & $45 / 100$ & 2 & 0 & 98 & 0 & 0 \\
\hline H33 & $100 / 100$ & 10 & 0 & 87 & 3 & 0 \\
\hline H34 & $12 / 100$ & 25 & 0 & 25 & 9 & 41 \\
\hline H35 & $100 / 100$ & 2 & 0 & 84 & 8 & 6 \\
\hline H36 & $100 / 100$ & 1 & 0 & 98 & 1 & 0 \\
\hline H37 & $100 / 100$ & 1 & 0 & 89 & 2 & 8 \\
\hline H38 & $100 / 100$ & 1 & 0 & 97 & 1 & 1 \\
\hline H39 & $30 / 100$ & 7 & 0 & 86 & 7 & 0 \\
\hline average & - & 4,97 & 2,38 & 84,85 & 5,03 & 2,89 \\
\hline
\end{tabular}

Source: Author (Empirical research)

Legend: ws. p.c. num. - Number of web pages crawled on each hotel website,

g.l. num. - Number of web pages analyzed within the Semrush Guru license.

Based on the data presented in Table 2 obtained through the web site crawled pages analysis of $5^{*}$ hotels in the Republic of Croatia, it can be seen that there are no $5^{*}$ hotels in the Republic of Croatia whose website is absolutely healthy. The analysis of the crawled pages shows that there is a lot of room (based on a large number of "Have issues" markers, with $84.9 \%$ as the average value of the analyzed websites of $5 *$ hotels in Croatia) to improve the quality of the websites of $5 *$ hotels in Croatia. The listed "Have issues", "Broken" "Redirected" and "Blocked" markers concern problems such as: page could not be crawled, broken links, returned 4xx status code, duplicate title tags, duplicate meta description, source code conflict, incomplete JavaScript and CSS file, low text to HTML ratio, no meta description, pages with low word count, sitemap.xml not found, sitemap.xml not indexed in robot.txt,... etc. It should be noted that out of the analyzed 100 pages, no intervention is required only on $4.97 \%$ of the pages. The data presented show that there is much room for improvement of hotel websites related to the improvement of website performance, which directly affects the quality of indexing, rating and archiving of web pages by search engine.

\subsection{Hotel Web Site Audit - Health Score Analysis}

The site health score is based on the number of total errors and total warnings found on web pages indexed within the site. Errors have a greater impact on the site health score than warnings, so it is recommended that errors be corrected first to improve the overall score. Web site Audit has over 130 checks / markers that the analysis tool checks for. Web site Audit also provides a list of notices, but errors certainly have more weight on the Web site Health Score compared to warnings and notices. 
ToSEE - Tourism in Southern and Eastern Europe, Vol. 6, pp. 739-756, 2021.

M. Šimunić: HOTEL'S WEB SITE HEALTH AUDIT AND PAGES DISTRIBUTION BY THEIR ...

Table 3: Web site audit - Health Score Level and Structure analysis

\begin{tabular}{|c|c|c|c|c|}
\hline \multirow{2}{*}{ Hotel } & \multicolumn{4}{|c|}{$\begin{array}{c}\text { WEB SITE AUDIT } \\
\text { Web site Health Score of } 5^{*} \text { Hotels in Croatia }\end{array}$} \\
\hline & Health Score $(\%)$ & Errors (number) & Warnings (number) & Notices (number) \\
\hline H1 & 66 & 30 & 365 & 193 \\
\hline H2 & 77 & 6 & 1735 & 163 \\
\hline H3 & 79 & 18 & 1406 & 433 \\
\hline H4 & 81 & 18 & 268 & 433 \\
\hline H5 & 81 & 18 & 268 & 433 \\
\hline H6 & 81 & 18 & 268 & 433 \\
\hline H7 & 81 & 18 & 268 & 433 \\
\hline H8 & 76 & 62 & 667 & 141 \\
\hline H9 & 58 & 281 & 1741 & 414 \\
\hline H10 & 67 & 189 & 3140 & 479 \\
\hline H11 & 84 & 33 & 180 & 873 \\
\hline H12 & 77 & 7 & 1722 & 186 \\
\hline H13 & 64 & 60 & 900 & 380 \\
\hline H14 & 75 & 8 & 2169 & 66 \\
\hline H15 & 88 & 11 & 200 & 663 \\
\hline H16 & 68 & 149 & 712 & 174 \\
\hline H17 & 77 & 92 & 93 & 17634 \\
\hline H18 & 81 & 3 & 1992 & 592 \\
\hline H19 & 81 & 3 & 2042 & 593 \\
\hline H20 & 50 & 863 & 728 & 330 \\
\hline H21 & 76 & 103 & 1332 & 193 \\
\hline H22 & 73 & 13 & 378 & 504 \\
\hline H23 & 70 & 32 & 3635 & 102 \\
\hline H24 & 81 & 30 & 1020 & 7797 \\
\hline H25 & 73 & 13 & 378 & 504 \\
\hline H26 & 61 & 519 & 6433 & 198 \\
\hline H27 & 92 & 0 & 830 & 1073 \\
\hline H28 & 81 & 4 & 436 & 531 \\
\hline H29 & 80 & 4 & 462 & 540 \\
\hline H30 & 64 & 360 & 455 & 907 \\
\hline H31 & 79 & 1044 & 175 & 176 \\
\hline H32 & 72 & 230 & 852 & 986 \\
\hline H33 & 92 & 2 & 155 & 29 \\
\hline H34 & 95 & 0 & 7 & 61 \\
\hline H35 & 77 & 108 & 3058 & 146 \\
\hline H36 & 88 & 3 & 290 & 47 \\
\hline H37 & 84 & 7 & 200 & 288 \\
\hline H38 & 69 & 192 & 375 & 770 \\
\hline H39 & 91 & 0 & 66 & 71 \\
\hline Average & 76,66 \% Healt Score & 116,69 Errors & 1061,56 Warnings & $\mathbf{1 0 2 4 , 8 5}$ Notices \\
\hline
\end{tabular}

Source: Author 
ToSEE - Tourism in Southern and Eastern Europe, Vol. 6, pp. 739-756, 2021.

Figure 3: Website audit - Health Score Level

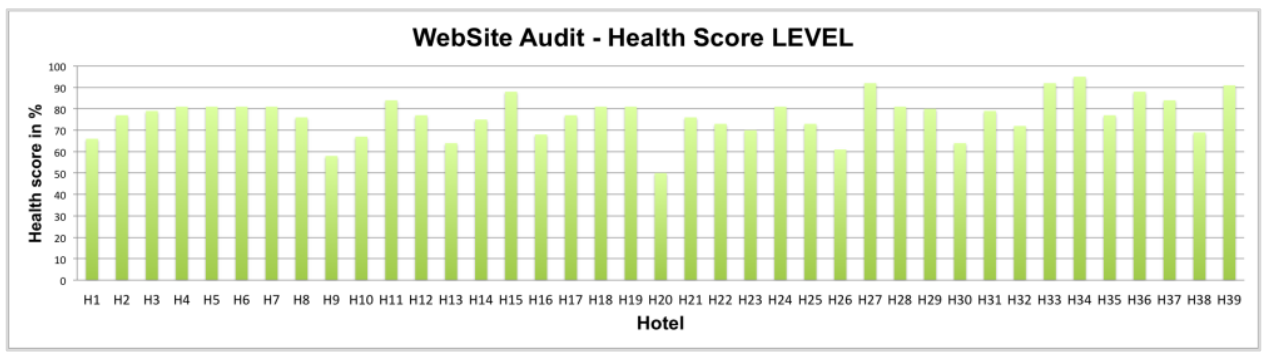

Source: Author

Figure 4: WebSite Audit - Health Score Structure

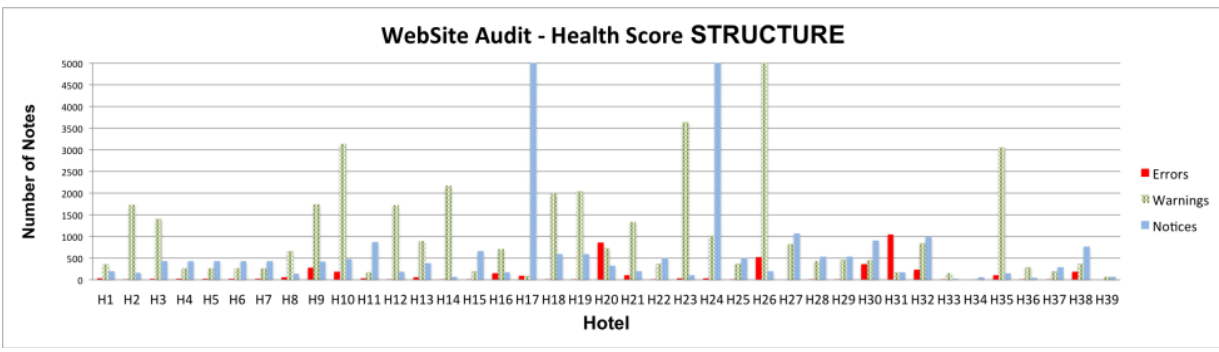

Source: Author

Based on Table 3 and Figure 3 and Figure 4, we see that the average health of a $5^{*}$ hotel website in the Republic of Croatia is $76.6 \%$. This figure was determined based on the calculated health levels of the websites of each hotel. The level of health of each hotel was determined based on a depth of analysis of 100 websites of each hotel website. As part of the website audit, analytical markers measure the number of errors, warnings, and notices on the analyzed pages. Each analytical marker has its place, weight and impact on the final website quality score expressed in terms of WebSite Health (\%). For each individual hotel website analyzed, the top 3 issues that had an impact on the health status of the observed website are listed. For example, the health status of the website of a hotel marked $\mathrm{H} 24$ is $81 \%$. This rating was obtained based on 30 errorsa, 1020 warningsa \& 7797 notices. In the top 3 errors, the Semrush website audit report pointed out (1) 1 page with slow loading speed, (2) 1 error with mixed content, and (3) 1 page with a 4XX status code. The system also registered 23 broken internal links within 30 errors. Other registered errors include: Page source code conflict, an incorrect page found in site.map, pages that returned a $4 x x$ status code, an incorrect page found in sitemap.xml, problems with incorrect hreflang links, and pages with slow loading speeds. In terms of warnings (in the sense of defects), the analysis showed that Hotel $\mathrm{H} 24$, for example, has a total of 1020 registered warnings on its website. Of these, 524 warnings relate to images without alt attributes (alt attributes within tags are used by search engines to understand the content of images, which is extremely important in tourism) (Barysevich 2020). Exactly 354 warnings are related to problems with non-minified JavaScript and CSS files 
ToSEE - Tourism in Southern and Eastern Europe, Vol. 6, pp. 739-756, 2021.

M. Šimunić: HOTEL'S WEB SITE HEALTH AUDIT AND PAGES DISTRIBUTION BY THEIR ...

(minification is the process of removing unnecessary lines, spaces and comments from source code. Minifying JavaScript and CSS lines reduces their size, which reduces page load time, creates a better user experience, and improves search engine rankings), while 74 warnings refer to a low text-to-HTML ratio. Other warnings or notices include: Pages not having $\mathrm{h} 1$ heading tags, pages not having a meta description, pages with too much text within the title tags (most search engines cut off titles that contain more than 70 characters) and sitemap.xml is not included in the robots.txt file, etc. Notices also have an impact on the final Health Score, but listing and editing them is beyond the scope of this article. As part of the Website Health Audit for a more in-depth analysis, Thematic Reports were used. They provide a more detailed look at the data on which the Website Health Score was calculated. These reports are: CRAWLABILITY Report (analysis of crawl depth and quality), HTTPS Report (analysis of security and architecture), INTERNATIONAL SEO Report (analysis of language / hreflang attributes), SITE PERFORMANCE Report (code, CSS \& javascript issues related to speed), INTERNAL LINKING Report (analysis of links \& clicks), MARKUP Report (data structure).

\subsection{Backlink Audit - (Domain analysis according to Toxic Score)}

Backlink Audit looks at hotel web site domain's backlink (incoming links to a website or web page from another resource) profile in order to help hotel as business subject to avoid Google penalties related to toxic backlinks. Backlink Audit analytics allows hotels to analyze the toxicity of domains. The Toxicity Score of a website is based on both (1) the number of toxic backlinks leading to the website and (2) the importance of the toxic markers found. In the context of this analysis, the most important features are (1) Referring Domains, which examines the total number of active referring domains that have at least one link leading to the analyzed domain, subpath, or URL, and (2) Analyzed Backlinks which examines the total number of active backlinks coming from referring domains to the analyzed domain. For each referring domain, Semrush analyzes the top 500 URLs

Figure 5: Hotels WebSites Backlink Audit Toxic status

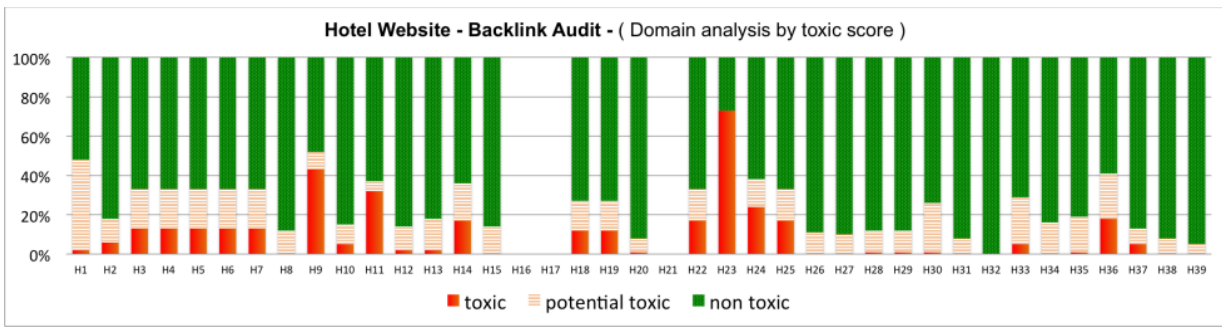

Source: Author

Google rates backlinks as "voices" from specific web pages that lead to a hotel web page that says, "This is a good hotel." Sites with a large number of backlinks from other sites tend to have high organic search engine rankings. The analysis of the toxicity of backlinks shows that the average health rating of $5^{*}$ hotel websites in the Republic of 
ToSEE - Tourism in Southern and Eastern Europe, Vol. 6, pp. 739-756, 2021.

M. Šimunić: HOTEL'S WEB SITE HEALTH AUDIT AND PAGES DISTRIBUTION BY THEIR ...

Croatia is at the level of $75.61 \%$. The shown toxicity ratings of $5 *$ hotel websites in Republic of Croatia (for each hotel website) were obtained based on the following markers: referring domains, (new, broken, lost), counted backlinks (new, broken, lost), domain authority score (authority score is a metric used to measure the overall quality and influence of a domain on SEO. The score is based on the number of backlinks, referring domains, organic search traffic and other specific data), Top referring domain categories (The distribution of referring domains by category. This is a good way to analyze in which niche there is interest in this website), Referring Domain by Authority Score (This chart helps to understand the overall quality and strength of the backlink profile of the analyzed domain. The more domains with a high Authority Score, the better), Backlink by Anchor Type (A breakdown of backlinks by their anchor type. Anchor text is the visible text of a backlink - the text you click on: money, compound, branded, organic, other, naked, empty), Top 100 Anchors (The most popular anchor texts linking to an analyzed domain. The popularity of each anchor is determined by the number of backlinks using it), top target pages (pages with the best performance on the site), backlinks by attributes (The ratio of follow vs. nofollow links, sponsored links and UGC links - User Generated Content links is one of many metrics a search engine can examine as a possible flag for policy violations), backlinks by link type (text, image, frame, form). Backlink analysis should be examined in detail. The quality of the markers based on which the overall backlink toxicity score was assigned should be analyzed to draw the right conclusions and define the directions for further better optimization and backlink building.

\section{CONCLUSION}

Business processes in the hotel (especially sales activities) are increasingly related to the use of network technologies (online resources as booking and sales channels). Hotel sales strategies are increasingly influencing hotel Key Performance Indicators. Based on theoretical knowledge from scientific research and experience from business practice, the facts show that today hotels sell more than $90 \%$ of their capacity in the online environment. Hotels can sell their capacities through direct and indirect sales channels. The distribution structure of online booking / sales channels of hotels is still dominated by sales through Online Travel Agencies with approx. between 70-80\% in Europe and the Republic of Croatia. The share of sales through the hotel brand web site is at the level of about $20 \%$ of all online booking channels). The hotel as a business system should constantly improve its sales channel management strategy that ensures the best ratio between direct and indirect sales channels. It is best for a hotel to sell as much of its capacity as possible directly through the hotel brand web site. The level of sales / booking through the hotel brand web site is acted upon through SEO - Search Engine Optimization (onSite, offSite) and through SEM - search engine marketing (Google Ads). In this paper, the focus is on the processes and elements of Search Engine Optimization. The level of direct online sales through the hotel brand web site is directly affected by visibility within organic / algorithmic Search Engine Resault Pages. Better visibility means better traffic to the hotel's web site. Better traffic results in more conversions, which implies a better business result. Visibility within search engines depends on the quality of optimization (OnSite and OffSite) of the Google ranking factor. These facts clearly indicate that there is a direct relationship between the quality of hotel 
ToSEE - Tourism in Southern and Eastern Europe, Vol. 6, pp. 739-756, 2021.

M. Šimunić: HOTEL'S WEB SITE HEALTH AUDIT AND PAGES DISTRIBUTION BY THEIR ...

web sites and the distribution structure of hotel online booking/sales channels. Marker metrics as a Google ranking factor within the hotel's web sites were conducted through Semrush Software. The analysis of metric markers as a Google ranking factor within the hotel web site provides insight into the general health of the hotel web site. For the purposes of the research presented in this paper, complex Full web site Audit Analysis and Backlinks Audit Analysis were conducted for the of each $5 *$ hotel in the Republic of Croatia. Based on the crawled pages analysis it can be observed that there is a lot of room to improve the quality of the websites of $5 *$ hotels in Croatia. It should be noted that out of the analyzed 100 pages, most of them are with "have issues" markers and "no intervention" /healthy status is required only on small numbers of pages of the web pages. These markers are mainly related to shortcomings of a technical nature and can be easily improved.The website health score audit is based on the number of total errors, total warnings and total notices found on web pages indexed within the website where errors certainly have more weight on the web site Health Score compared to warnings and notices. As part of the hotel website health analytical process (through 130 markers) the technical and content aspects of the hotel websites were analyzed at the same time. Looking at the average health of the $5^{*}$ hotel website in the Republic of Croatia and taking into account the relatively large average number of errors, warnings and remarks it can be concluded that there is great potential for improvement in this regard too. Domain toxicity analysis is the result of long-term effort and investment in content on the hotel's website. The analysis of the backlinks' toxicity shows that within the websites of a $5^{*}$ hotel in the Republic of Croatia, there are a lot of shortcomings. In order to influence the improvement of hotel business, efforts should be made to improve the quality of all metrics markers as elements that affect the quality of website content. Increasing the quality of these factors will directly affects better search engine visibility / better position within the search engine resault pages and the achievement of better hotel booking/sales through the hotel brand website. The results of empirical research conducted for the purposes of this paper show that $(1)$ within the websites of $5^{*}$ hotels in the Republic of Croatia there is significant potential to improve their optimization quality, (2) based on the analysis of the type of deficiencies it is possible to determine where web site deficiencies are most dominant. Such insights certainly represent one of the important ways to make positive impact on the success of each individual hotel business. 
ToSEE - Tourism in Southern and Eastern Europe, Vol. 6, pp. 739-756, 2021.

M. Šimunić: HOTEL'S WEB SITE HEALTH AUDIT AND PAGES DISTRIBUTION BY THEIR ...

\section{REFERENCES}

Aazim, A. (2021), "Google Ranking Factors for 2021 (10 Are Most Important)", MonsterInsights, https://www.monsterinsights.com/Google-ranking-factors/, accesswed: 18.04.2021.

Abiantoro, D. and Kusumo, D.S. (2020), "Analysis of Web Content Quality Information on the Koseeker Website Using the Web Content Audit Method and ParseHub Tools", 8th International Conference on Information and Communication Technology (ICoICT), 2020, pp. 1-6, doi: 10.1109/ICoICT49345.2020.9166396

Alba-Muñoz, S., Rojas-de-Gracia, M. and Sierra-Herrezuelo, P. (2021), "Usability Audit Model for Tourism Destination Websites", in Das, S.and Mondal, S. (Ed.), Innovations in Digital Branding and Content Marketing, IGI Global, pp. 160-188. http://doi:10.4018/978-1-7998-4420-4.ch008

Bailyn, E. (2020), "The 2021 Google Algorithm Ranking Factors", FirstPageSage, https://firstpagesage.com/seo-blog/seo-faqs/the-2021-Google-algorithm-ranking-factors-fc/, Accessed: 03.05.2021.

Buhalis, D. and Law, R. (2008.) "Progress in Information Technology and Tourism Management: 20 Years on and 10 Years after the Internet-The State of eTourism Research", Tourism Management, Vol. 29, pp. 609-623.

Barysevich, A. (2020), "Google ranking factors to change search in 2021: Core Web Vitals, E-A-T, or AMP?", Search Engine Watch, https://www.searchenginewatch.com/2020/09/16/Google-ranking-factors2021-core-web-vitals-e-a-t-or-amp/, access: 20.02.2021.

Beritelli, P. and Schegg, R. (2016), "Maximizing online bookings through a multi-channelstrategy", International Journal of Contemporary Hospitality Management, Vol. 28, No. 1, 68-88. https://doi.org/10.1108/IJCHM-07-2014-0326

Brian, D. (2020), “Google's 200 Ranking Factors: The complete List (2021)”, Backlinko, https://backlinko.com/Google-ranking-factors, access: 05.02.2021.

Connally, K.C. (2021), Why travel brands need to reconsider direct bookings, Hotel Management, https://www.hotelmanagement.net/operate/why-travel-brands-need-to-reconsider-direct-bookings, access: 25.01 .2021

Connor, L. (2020), "15 Google SEO Success Factors That Could Impact Your Site", SemrushBlog, https://www.semrush.com/blog/seo-ranking/, accessed: 25.04.2021.

Deane, S. (2020), "Over 60 Online Travel Booking Statistics (2020)", StratosJets, https://www.stratosjets.com/blog/online-travel-statistics/, access: 20.02.2021.

Dowson, M. (2021), "12 ranking factors that matter to Google for 2021", Ragan's PR Daily, https://www.prdaily.com/12-ranking-factors-that-matter-to-Google-for-2021/, accessed 04.05.2021.

d-edge hospitality. (2021), "The rise of direct bookings over OTAs, Hotel distribution trends in EMEA and APAC from 2017 to 2020.”, https://www.d-edge.com/the-rise-of-direct-bookings-over-otas/, 29.01.2021.

Fei, Y., Hui, Y. and Wu, Y. (2017), ’Optimal online channel strategies for a hotel considering direct booking and cooperation with an online travel agent", International Transactions in Operational Research, Vol. 26, No. 3, pp. 968-998. https://doi.org/10.1111/itor.12470

Hardwick, J. (2021), “10 Google Ranking Factors You Shouldn't Ignore”, Ahrefs, https://ahrefs.com/blog/Google-ranking-factors/, accessed: 15.04.2021.

Lei, S.S.I., Nicolau, J.L. and Wang, D. (2019), "The impact of distribution channels on budget hotel performance", International Journal of Hospitality Management, Vol. 81, pp. 141-149. https://doi.org/10.1016/j.ijhm.2019.03.005

Mihač, V. (2019), “Sustavi i trendovi u online prodaji hotelskog smještaja u Republici Hrvatskoj”, Magistarski rad, DOBA Fakultet za primjenjene poslovne i društvene studije, Maribor, 2019.

Mohsin, M. (2020), "10 Google Search Statistics You need to know in 2020 [Infographic], Oberlo, 03.04.2020. https://Google.oberlo.com/blog/Google-search-statistics), access: 15.06.2020.

Nada, A. (2021), 10 Most Decisive Google (SEO) Ranking Factors in 2021, Uptimiser, 2021. https://www.uptimiser.com.hk/seo-google-ranking-factors/, accessed: 01.05.2021.

Prieto, M. (2021.)"How to Grow Hotel Direct Bookings", Medium, https://medium.com/traveltechmedia/howto-grow-hotel-direct-bookings-403414842469, access: 01.02.2021.

Robinson, J. (2019), "5 Top Resources for Google Ranking Factors", SEJ, Search Engine Journal, April 24 2019. https://Google.searchenginejournal.com/Google-ranking-factors-resources/304125/\#close.

Sravan K.K. (2021), "SEMrush Site Audit Tool - Everything you need to know", WittySparks, https://wittysparks.com/semrush-site-audit-tool-review/, accessed: 11.04.2021. 
ToSEE - Tourism in Southern and Eastern Europe, Vol. 6, pp. 739-756, 2021.

M. Šimunić: HOTEL'S WEB SITE HEALTH AUDIT AND PAGES DISTRIBUTION BY THEIR

Šimunić, M., Car, T., Vitezić, V. (2019), "Improving Direct Online Sales in the Hotel Industry: Expanded paradigm varariables of Google Algorithms for Ranking", IMR - 2019, Interdisciplinary Management Research XV, pp- 1087-1109.

Šimunić, M. (2020), "The importance of hotel's web site performance for generating higher search engine visibility", 4th Conference on Economics and Management - EMAN 2020, pp. 431-448. doi: https://doi.org/10.31410/EMAN.2020.431

Thielin, F. (2020), 4 ways to get more Hotel Bookings, Hotelminder.com, https://www.hotelminder.com/4 ways-to-get-more-hotel-bookings, access: 05.02.2021

Tober, M. (2021), "The Impact of Core Web Vitals on Website Performance in Google Search Result", Searchmetrics, https://www.searchmetrics.com/knowledge-hub/studies/core-web-vitals-studyapril2021/?utm_source=Google\&utm_medium=cpc\&utm_campaign=Brand_Europe_English\&ut m_adgroup=Ranking_Factors\&utm_term=ranking\%20factors\&gclid=EAIaIQobChMIrrPfs87E8 AIVCON3Ch3VGAdMEAAYASAAEgJbY_D_BwE, accessed: 03.05.2021.

Ziakis, C. Vlachopoulou, M. Kyrkoudis, T., Karagkiozidou, M. (2019), "Important Factors for Improving Google Search Rank" Future Internet, Vol. 11, No. 2, 32. https://doi.org/10.3390/fi11020032

Mislav Šimunić, Ph.D, Full Professor

University of Rijeka, Facult of Tourism and Hospitality Management, Department of Informatics

Primorska 46, 51410 Opatija, Croatia

$+385-51-294180$

mislavs@fthm.hr 